\title{
Avaliação da qualidade da água no Sistema Produtor Taquacetuba - Guarapiranga, SP, Brasil
}

\author{
Assessement of water quality in the Taquacetuba - Guarapiranga Producer System, \\ SP, Brazil
}

\author{
Rômulo André Santos Silva' \\ Denise Conceição de Gois Santos Michelan ${ }^{2(*)}$
}

\section{Resumo}

O presente estudo tem como objetivo avaliar a qualidade da água transferida da represa Billings para a Guarapiranga por meio do Sistema Produtor Taquacetuba-Guarapiranga, utilizando-se de parâmetros físicos, químicos e microbiológicos. A avaliação deu-se por meio da obtenção de dados de monitoramento dos parâmetros condutividade elétrica $(\mathrm{CE})$, cor aparente, demanda biológica de oxigênio (DBO), fósforo total, nitrogênio amoniacal, nitrito, nitrato, oxigênio dissolvido (OD), pH, turbidez, Escherichia coli e cianobactérias disponibilizados pela Companhia de Saneamento Básico do Estado de São Paulo (SABESP), relativos ao ano de 2018. Foram selecionados dois pontos para análise, BL 105 (Represa Billings) e GU 101 (Represa Guarapiranga) e os valores foram comparados com a resolução CONAMA 357/05. Como resultado, alguns parâmetros estiveram dentro dos limites estabelecidos, como $\mathrm{pH}(6,47-9,20)$, turbidez $(2,20-50,20$ NTU) e E. coli (1 - 517 NMP.100mL-1), no entanto, os parâmetros fósforo total, DBO, OD e cianobactérias, apresentam valores em desconformidades com a legislação vigente. Esses valores podem estar relacionados com as fontes pontuais de contaminação por esgotos domésticos que são lançados de forma irregular e acabam ocasionando a eutrofização das represas. Com a transferência das águas da Billings para Guarapiranga, corrobora com a degradação da mesma. Conclui-se que, para reduzir/ minimizar esse problema, sejam realizadas medidas preventivas e conservacionistas por intermédio de ações.

Palavras-chave: Efluentes domésticos, Indicadores de qualidade, CONAMA 357

\section{Abstract}

The present study aims to evaluate the quality of water transferred from Billings water dam to Guarapiranga through the Taquecetuba-Guarapiranga Producer System, using physical, chemical and microbiological parameters. The evaluation was made by obtaining monitoring data for electrical conductivity (EC), apparent color, biological oxygen demand (BOD), total phosphorus, ammonia nitrogen, nitrite, nitrate, dissolved oxygen, $\mathrm{pH}$, turbidity, Escherichia coli and cyanobacteria provided by the São Paulo Basic Sanitation Company (SABESP) for the year 2018. Two points were selected for analysis, BL 105 (Billings Water Dam) and 101 GU (Guarapiranga Water Dam) and the values

I Engenheiro do Petróleo; Universidade Federal de Sergipe, UFS; Endereço: Av Marechal Rondon, s/n, Jardim Rosa Elze, CEP: 49100-000, São Cristóvão-SE, Brasil; E-mail: romuloandre_555@hotmail.com

2 Dra.; Engenheira Civil; Professora da Universidade Federal de Sergipe, UFS; Endereço:Av Marechal Rondon, s/n, Jardim Rosa Elze, CEP: 49100-000, São Cristóvão-SE, Brasil; E-mail: denise_gois@yahoo.com.br (*) Autor para correspondência Recebido para publicação em 22/07/2019 e aceito em 24/09/2019

\begin{tabular}{llllll}
\hline Ambiência & Guarapuava (PR) & v.l5 n.2 & p. 343 - 355 & Maio/Ago 20I9 & ISSN I808 - 025I
\end{tabular}


were compared with the CONAMA Resolution 357/05. As a result, some parameters were within the established limits, such as $\mathrm{pH}(6.47-9.20)$, turbidity $(2.20-50.20$ NTU) and E. coli $\left(1-517\right.$ NMP.100 $\left.\mathrm{mL}^{-1}\right)$, however, the total phosphorus, BOD, DO and cyanobacteria parameters are not in accordance with current legislation. These values may be related to the contamination point sources by domestic sewage that are released irregularly and end up eutrophizing the water dams and, with the water transfer from Billings to Guarapiranga, corroborates its degradation. It is concluded that, in order to reduce and/or minimize this issue, preventive and conservation measures should be taken.

Key words: Domestic effluents, Quality Indicators, CONAMA 357

\section{Introdução}

A escassez de recursos naturais utilizados para o suprimento das atividades humanas tornou-se um dos grandes problemas enfrentados atualmente pela sociedade atrelado as crescentes demandas. No entanto, a água tem apresentado maior preocupação quanto a sua disponibilidade e qualidade adequada e vem sendo afetada diretamente por atividades antrópicas (YAN, 2016; SCHMITZ e BITTENCOURT, 2017).

A intensa urbanização em bacias hidrográficas tem propiciado a degradação da qualidade hídrica. Nesse sentido, o uso e ocupação do solo em áreas próximas a reservatórios que são utilizados para abastecimento humano, tem recebido cargas pontuais e difusas provindas de atividades domésticas, agrícolas e industriais colaborando com as alterações das propriedades físicas, químicas e microbiológicas da água (GUEDES et al, 2017; TADEU et al, 2017).

A degradação de corpos hídricos são mais perceptíveis em grandes centros urbanos como na Região Metropolitana de São Paulo (RMSP), que cresceu de forma acelerada e desordenada, gerando impactos negativos na qualidade das águas de seus mananciais, dado, principalmente, pela falta de infraestrutura de saneamento básico (FONTANA et al, 2014; DALMAS et al, 2015).

As represas de Billings e Guarapiranga são estratégicas para o fornecimento de água para RMSP. E por estarem inseridos em perímetro altamente antropizado, tornam-se ecossistemas propícios a eutrofização (QUEIROZ et al, 2015; FAUSTINO et al, 2016; MACHADO et al, 2016; BRITO; MIRAGLIA; SEMENSATTO, 2018).

Apesar da existência desses dois grandes reservatórios, a escassez de água comprometeu o abastecimento público e, como consequência, motivou a Companhia de Saneamento Básico de São Paulo (SABESP) a implementar o Sistema Produtor Taquacetuba-Guarapiranga, com o objetivo em realizar o bombeamento de água da represa Billings para a Guarapiranga, por meio de um sistema hidráulico, garantindo a demanda necessária. No entanto, surgiram questões ambientais envolvendo o empreendimento como: possível alteração da qualidade da água, desequilíbrio da biota aquática, tendo em vista que são mananciais com diferentes características (MENEZES et al, 2016).

Logo, é de fundamental importância realizar o monitoramento e/ou avaliação da qualidade das águas dos corpos hídricos (MORAIS et al, 2016).

Com base no exposto, este estudo objetivou avaliar a qualidade da água transferida da represa Billings para a Guarapiranga, por meio do Sistema Produtor Taquacetuba - Guarapiranga, utilizando-se de parâmetros físicos, químicos e microbiológicos. 


\section{Material e Métodos}

\section{Área de estudo}

A área de estudo corresponde às represas Billings e Guarapiranga, pertencentes à bacia hidrográfica do Alto Tietê. A Figura 1, apresenta a localização das represas em estudo.

Figura 1 - Visualização das represas Billings e Guarapiranga.

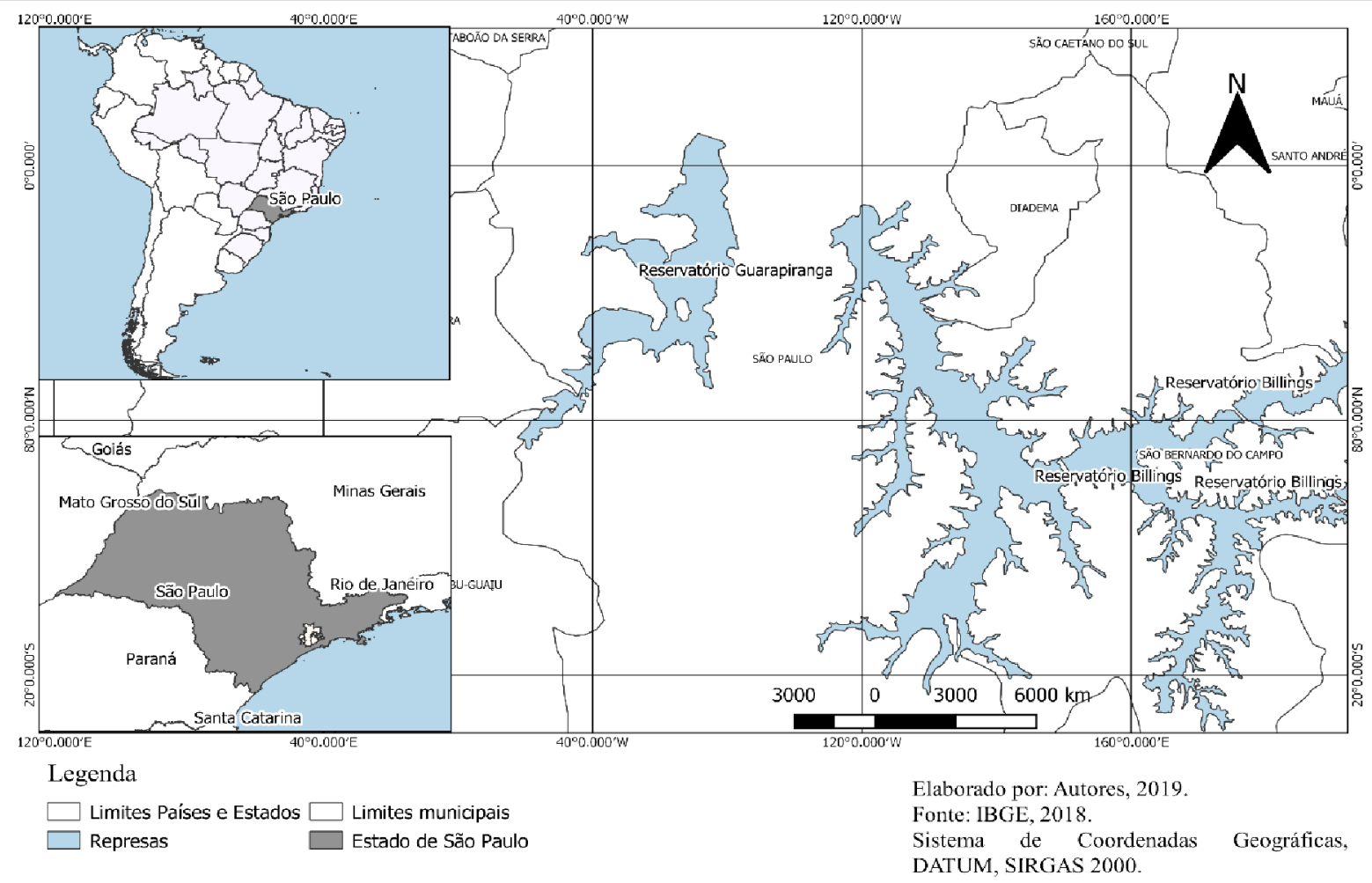

Fonte: SILVA e Michelan, 2019.

A Represa de Billings é a maior pertencente a bacia hidrográfica do Alto Tietê, com área de aproximadamente $120 \mathrm{~km}^{2}$ distribuído em um longo corpo central com oito braços, profundidade máxima de 18 metros, volume de $646,841 \times 10^{6} \mathrm{~m}^{3}$, fluxo de $8,75 \mathrm{~m}^{3} \cdot \mathrm{s}^{-1}$ e média de retenção de 720 dias (CETESB, 2014). O Braço Taquacetuba (um dos oito braços que compõe a represa) no ano de 2000 foi incluído no Programa Metropolitano de Água (PMA) que tem como objetivo garantir o suprimento de água a população da RMSP por meio do bombeamento de suas águas para a represa de Guarapiranga, que aporta na várzea do rio Parelheiros (CETESB, 2014).

O Braço Taquacetuba está inserido em uma área antropizada com a presença de propriedades irregulares, que atuam como fontes de poluição pontual e áreas agrícolas que acabam corroborando com o aporte de poluição difusa (CETESB, 2014; TADEU et al, 2017).

A Represa de Guarapiranga é considerada como a segunda maior presente na bacia do Alto Tietê abrangendo uma área de $33 \mathrm{~km}^{2}$, profundidade máxima de 13 metros e fornece $11 \mathrm{~m}^{3} . \mathrm{s}^{-1}$ para abastecimento de cerca de 20\% de toda a RMSP, atuando como um dos mais importantes fornecedores de água (CETESB, 2014). 


\section{Pontos de Amostragem}

Para avaliar a qualidade da água das represas em estudo foram selecionados dois pontos que apresentam monitoramento constante realizado pela Companhia de Saneamento Básico do Estado de São Paulo (SABESP). A Tabela 1 apresenta a descrição dos pontos selecionados, no qual os mesmos apresentam relevância quanto à transposição de águas do Braço Taquacetuba e na Figura 2, observa-se a localização dos pontos de monitoramento.

\section{Tabela 1 - Descrição dos pontos de avaliação, descrição e coordenadas geográficas.}

\begin{tabular}{ccc}
\hline Ponto & Descrição & Coordenadas \\
\hline \multirow{2}{*}{ BL 105 } & Captação de água no Braço Taquacetuba (Represa Billings) & $23^{\circ} 50^{\prime 2} 20^{\prime} \mathrm{S}$ \\
& para transposição a represa Guarapiranga. & $46^{\circ} 39^{\prime} 30^{\prime} \mathrm{O}$ \\
GU 101 & Várzea do rio Parelheiro local de chegada das águas provindas & $23^{\circ} 44^{\prime} 55^{\prime}$ S \\
& do Braço Taquacetuba. & $46^{\circ} 43^{\prime} 30^{\prime} \mathrm{O}$ \\
\hline
\end{tabular}

Fonte: SABESP (2018).

\section{Figura 2- Localização georeferenciada dos pontos de análise deste} estudo.

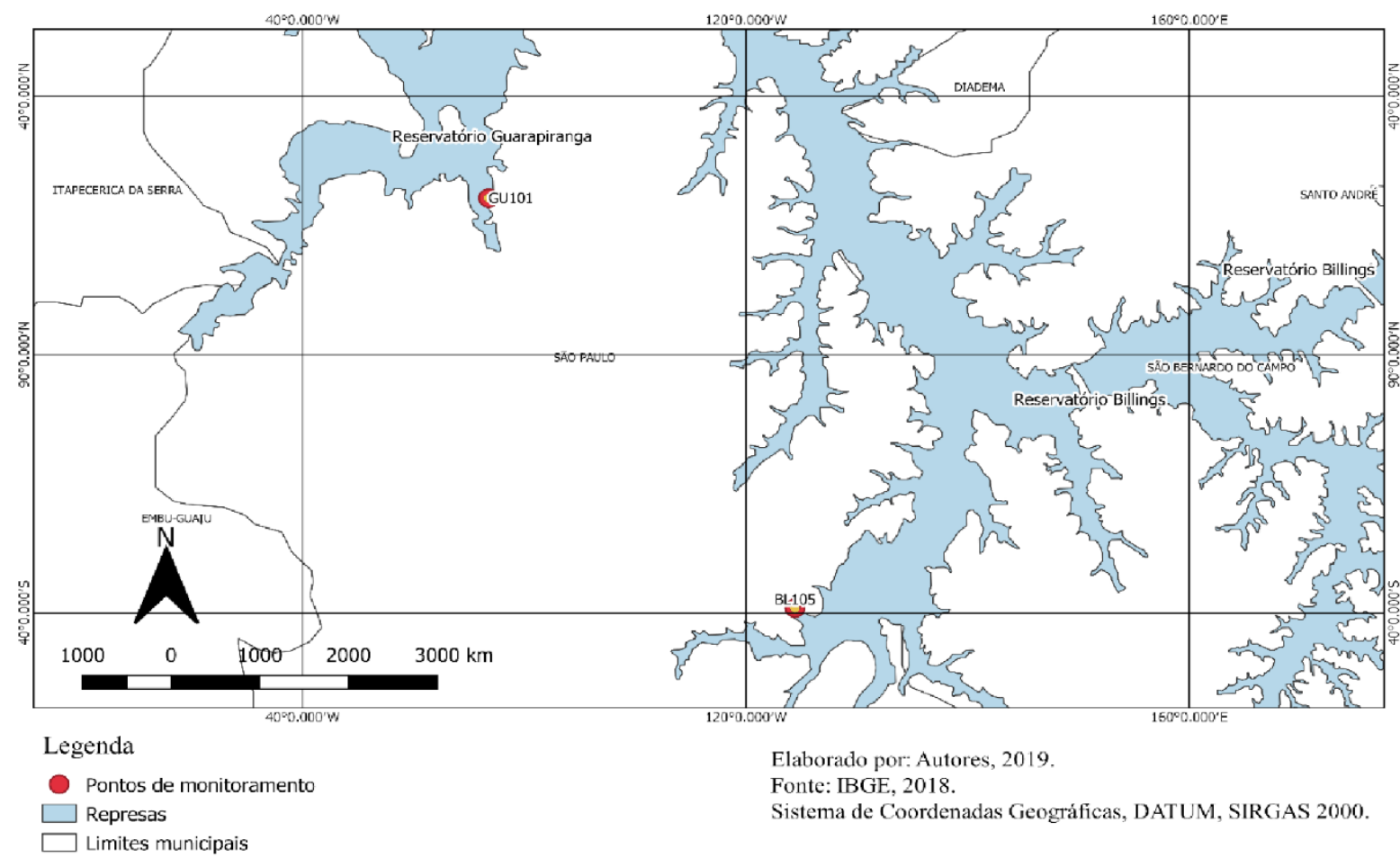

Fonte: SILVA e Michelan, 2019.

\section{Levantamento de Dados}

Os dados para análise da qualidade das águas das represas em estudo foram obtidos em planilhas fornecidas pela SABESP com valores de mensurações em todos os meses do ano de 


\begin{tabular}{|c|c|c|}
\hline Parâmetro de Qualidade & Unidade & VMP* \\
\hline Condutividade elétrica $(\mathrm{CE})$ & $\mu \mathrm{S} . \mathrm{cm}^{-1}$ & N.E.** \\
\hline Cor aparente & UC & N.E.** \\
\hline Demanda Biológica de Oxigênio (DBO) & mg. $L^{-1}$ & 3,00 \\
\hline Fósforo total & mg. $L^{-1}$ & 0,020 \\
\hline Nitrogênio amoniacal & mg. $L^{-1}$ & 2,00 \\
\hline Nitrito & mg. $L^{-1}$ & 1,00 \\
\hline Nitrato & mg. $L^{-1}$ & 10,00 \\
\hline Oxigênio dissolvido (OD) & mg. $L^{-1}$ & 6 \\
\hline $\mathrm{pH}$ & - & 6,0 a 9,0 \\
\hline Turbidez & NTU & 100 \\
\hline Escherichia coli & NPM.100mL-1 & 1.000 \\
\hline Cianobactérias & células.mL $L^{-1}$ & 50.000 \\
\hline
\end{tabular}

Fonte: CONAMA 357/05 (BRASIL, 2005). *Valor Máximo Permitido; **Não Estabelecido.

2018. Foram selecionados 12 parâmetros de qualidade que estão dispostos na Tabela 2, além dos valores máximos permitidos (VMP), estabelecidos pela Resolução CONAMA 357 de 2005 (BRASIL, 2005) no qual foram comparados.

\section{Resultados e Discussões}

De acordo com o padrão brasileiro de qualidade das águas (BRASIL, 2005), os presentes corpos hídricos foram classificados como água doce classe II. Sendo assim, a água pode ser destinada para consumo humano, após tratamento tradicional; proteção à comunidade aquática; contato para recreação primária; irrigação de vegetais e árvores frutíferas, plantas e jardins; áreas para prática de esportes e aquicultura.

Quanto à definição das estações para o ano de 2018, os meses entre maio e setembro foram caracterizados como secos e entre outubro a abril como chuvosos, de acordo com os dados de precipitação disponibilizados pelo Departamento de Águas e Energia Elétrica do Estado de São Paulo (DAEE) e apresentados na Figura 3.

Conforme os dados presentes nas planilhas disponibilizadas pela SABESP, os parâmetros cor aparente, $\mathrm{pH}$, turbidez, Escherichia coli, nitrogênio amoniacal, nitrito e nitrato não foram encontrados em concentrações acima dos limites estabelecidos pela resolução CONAMA 357/05 (BRASIL, 2005). As Tabelas 3 e 4, apresentam os valores máximos, mínimos e média para esses parâmetros no período seco e chuvoso, respectivamente.

Vale ressaltar que os valores de $\mathrm{pH}$, apresentam tendência alcalina, propiciando a proliferação de algas quando em concomitância significativa de concentrações de nutrientes (GÓIS e OLIVEIRA, 2014; MACHADO et al., 2016).

A Condutividade Elétrica (CE) não apresenta valores limites estabelecidos pela resolução CONAMA 357/05, no entanto, a CESTEB (2018) explícita em seu relatório Significado Ambiental e Sanitário das Variáveis de Qualidade que, em corpos hídricos que apresentam valores de condutividade acima de $100 \mu \mathrm{S} . \mathrm{cm}^{-1}$, existe indício de alteração decorrente do lançamento de efluentes domésticos. 


\section{Figura 3 - Média de precipitação mensal na região das duas represas no ano de 2018.}

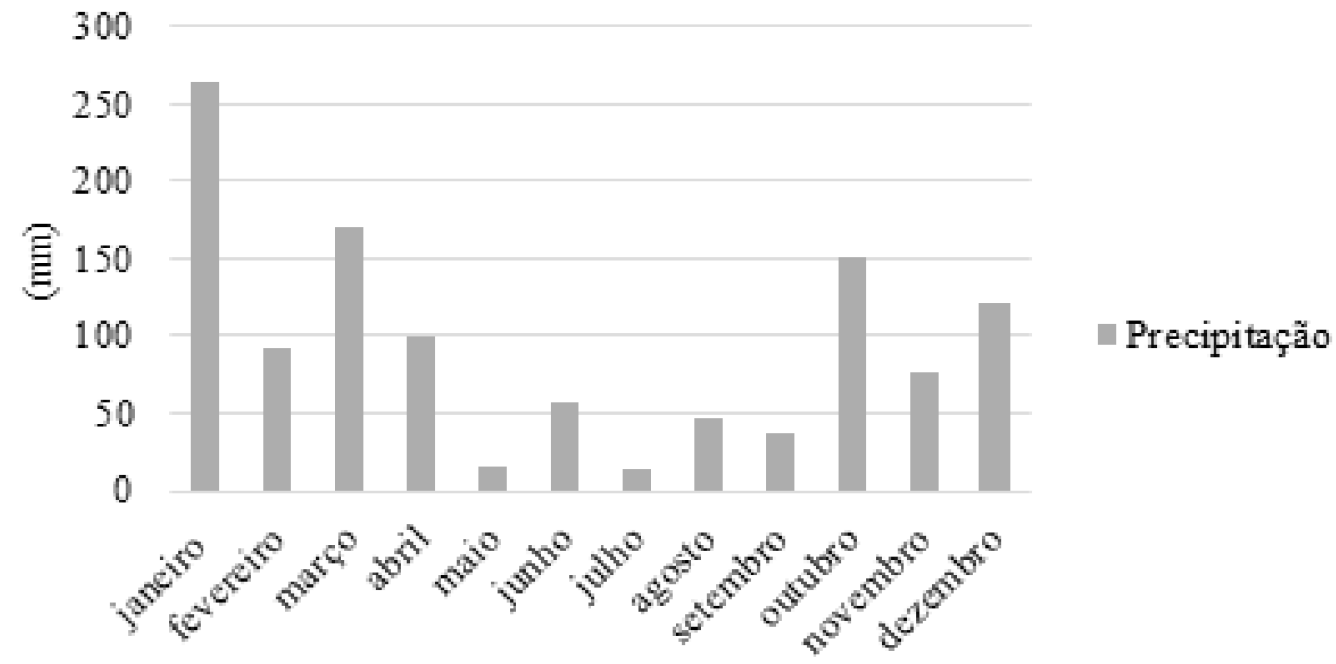

Fonte: Adaptado de DAEE (2018).

Levando em consideração essa premissa proposta pela CETESB e comparando com os dados medidos, tanto no ponto BL 105, no qual apresentou variação de CE entre 171,3 a 184,95 $\mu \mathrm{S} . \mathrm{cm}^{-1}$ e média de 177,04 $\pm 4,71 \mu \mathrm{S} . \mathrm{cm}^{-1}$; quanto no GU 101, com variação 130,1 a 150,62 com média 140,62 $\pm 6,89 \mu \mathrm{S} . \mathrm{cm}^{-1}$, em todos ocorreram extrapolação do valor proposto, com maiores concentrações no período seco, que pode estar relacionado com a redução da precipitação e o constante aporte de efluentes domésticos provindos de fontes pontuais, acarretando aumento da concentração de sais (POMPÊO et al., 2017). Esses valores medidos assemelham-se com os encontrados na Guarapiranga em estudo realizado por Machado e et al., (2016), com CE variando entre 44,7 a $203 \mu \mathrm{S} . \mathrm{cm}^{-1}$.

Com a transferência entre as duas represas é verificado que a Guarapiranga, apresenta menor concentração (Figura 4), porém, ainda permanece acima do $100 \mu \mathrm{S} . \mathrm{cm}^{-1}$, indicando que há alteração nesse meio.

Figura 4 - Dados de condutividade elétrica para os pontos em estudo.

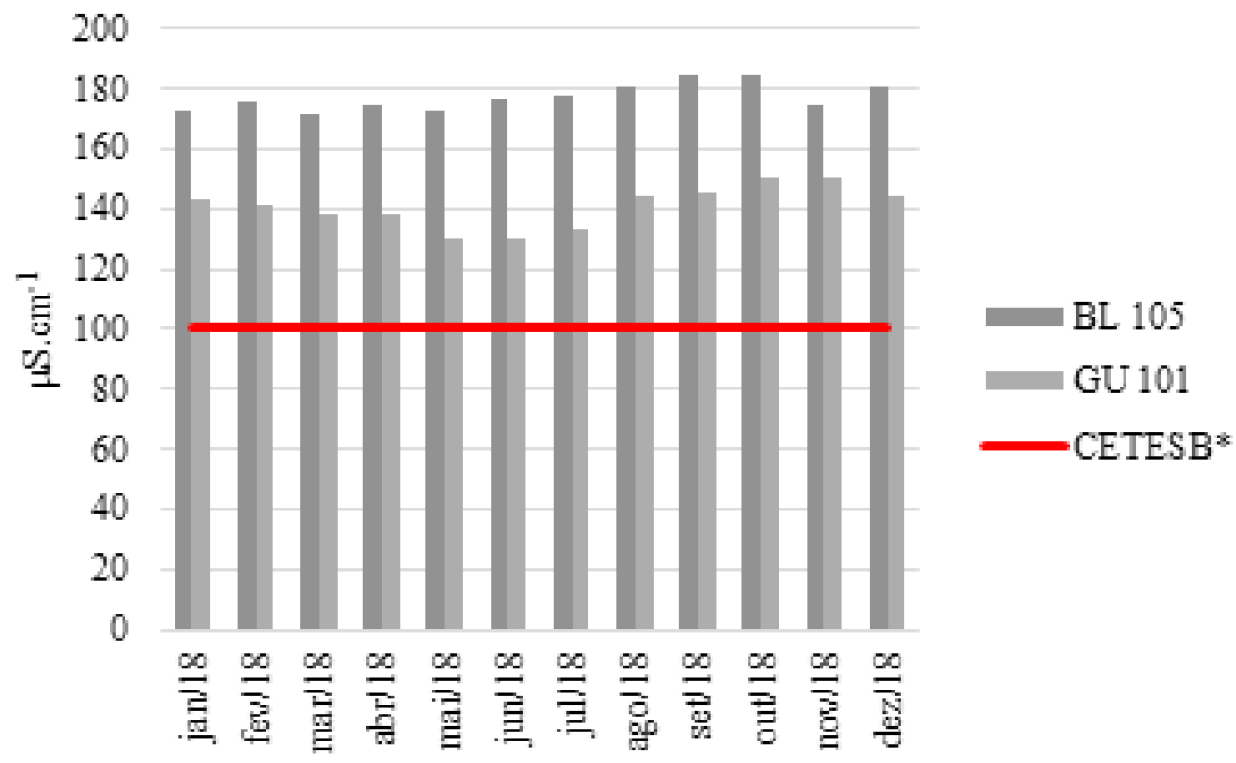

Fonte: Adaptado da SABESP (2018); *Limite sugerido pela CETESB (2018). 


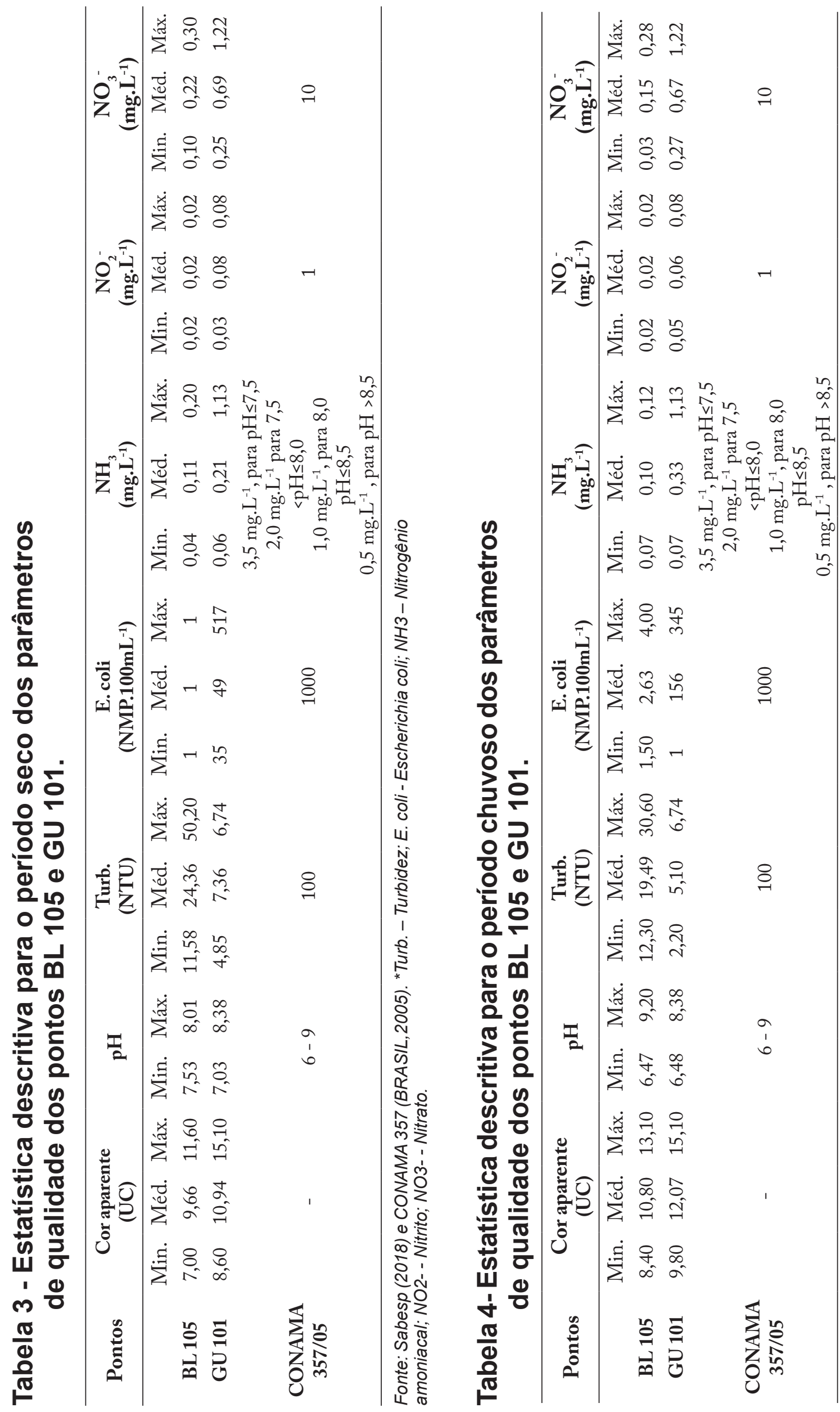

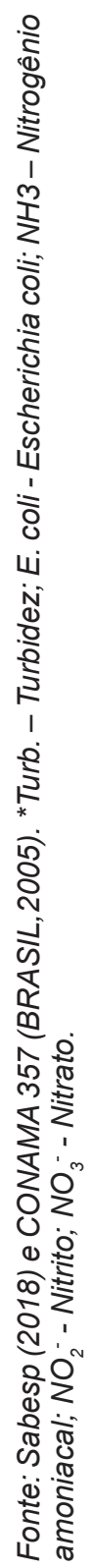

SILVA, R. A. S., MICHELAN, D. C. G. S. 
Em relação a DBO, a resolução CONAMA 357/05 estabelece concentração máxima de $5 \mathrm{mg} . \mathrm{L}^{-1}$ para corpos de água doce classe II. No entanto, esse valor é extrapolado nos meses de janeiro/18(chuvoso), junho e julho/18 (seco) no ponto BL 105 com concentrações de 7,0, 9,5 e 9,5 mg. $\mathrm{L}^{-1}$, respectivamente. Já quando transferidas para a Guarapiranga, ocorre aumento na DBO em $72 \%$ dos meses (Figura 5), podendo estar relacionado com a redução no processo de autodepuração hídrica na várzea do rio Parelheiros, provocado pelas ações antrópicas decorrentes da ocupação irregular do solo por núcleos urbanos, o que contribui com as poluições por fontes difusas e pontuais (COBRAPE, 2006). Valores próximos também foram relatados no relatório Qualidade das águas interiores no estado de São Paulo, no ano de 2017 no qual também indicaram que as altas concentrações de matéria orgânica se dão devido às ações antrópicas (CETESB, 2017).

\section{Figura 5 - Gráfico contendo os valores de DBO nos pontos estudados em comparação com a resolução CONAMA 357/2005.}

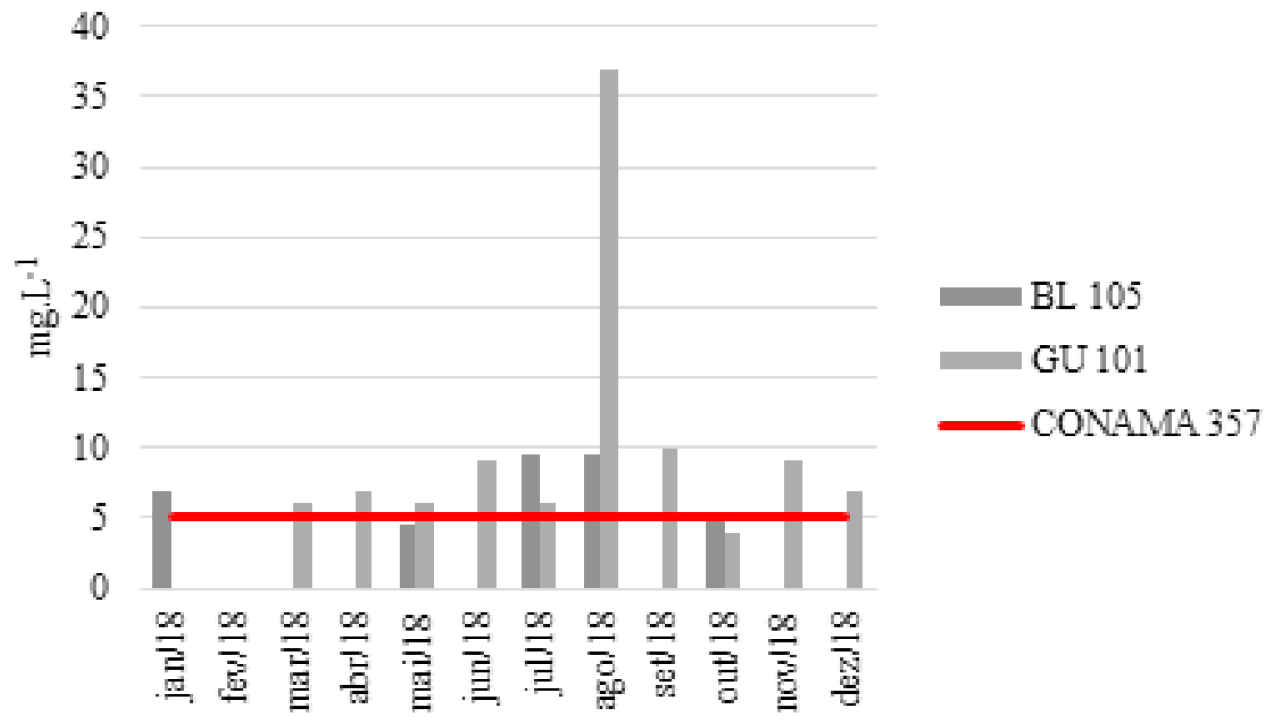

Fonte: Adaptado da SABESP (2018).

O VMP estabelecido para o parâmetro fósforo em corpos de água doce classe II, de acordo com o CONAMA 357/05 é de 0,02 mg. $\mathrm{L}^{-1}$, as concentrações mensuradas nos pontos em estudo estiveram acima em todos os meses do ano, como pode ser verificado na Figura 6. O BL 105, apresentou variação entre 0,038 a $0,10 \mathrm{mg} \cdot \mathrm{L}^{-1} \mathrm{com}$ média de $0,057 \pm 0,02 \mathrm{mg} \cdot \mathrm{L}^{-1}$ e o ponto $\mathrm{GU}$ 101 variou entre 0,04 a 0,10 mg. $\mathrm{L}^{-1}$ e média de 0,08 $\pm 0,02 \mathrm{mg} . \mathrm{L}^{-1}$. Com destaque para as águas da Guarapiranga que apresentam maior concentração de fósforo que a Billings em 83,33\% dos meses.

Esses resultados não conformes com a legislação são caracterizados devido à falta de coleta de esgotos sanitários, nas residências próximas ao entorno das represas, que acabam aportando esgoto doméstico sem o devido tratamento. A CETESB (2018), em estudo sobre a qualidade das águas dessas duas represas obteve $100 \%$ dos resultados em não conformidade com a legislação e constatou que com essas concentrações em excesso para o corpo hídrico aumenta a probabilidade de ocorrer a eutrofização e propicia o surgimento de algas em excesso (VÉLEZ-AZANÊRO et al., 2016). Um outro fator importante é o bombeamento da água do Braço Taquacetuba para a Guarapiranga que acaba por aumentar a concentração de fósforo (MACHADO et al., 2016).

O Oxigênio Dissolvido (OD) é um dos parâmetros mais importantes quando relacionado com a qualidade da água, pois é fonte de sobrevivência para os organismos aquáticos e, quando em baixas concentrações, atua como indicador de contaminação (CETESB, 2018). 


\section{Figura 6 - Gráfico contendo as mensurações das concentrações de fósforos nos pontos analisados diante do valor mínimo do CONAMA 357/2005, que é de 5 mg.t-1.}

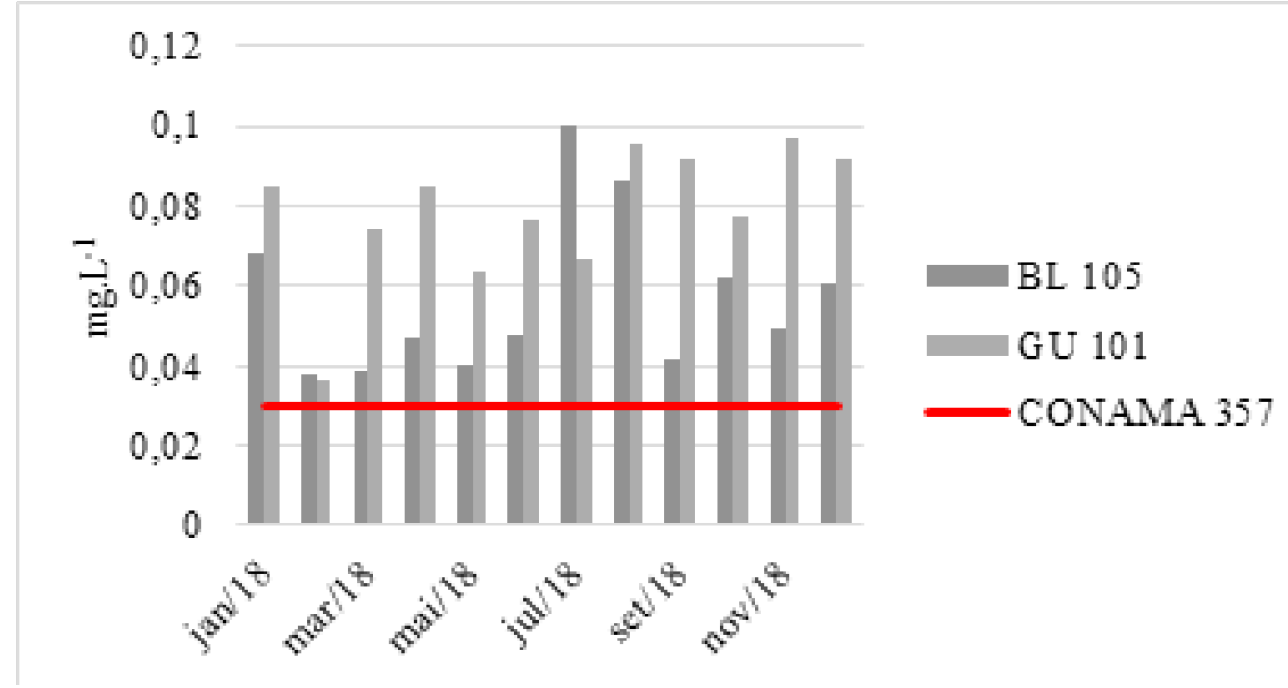

Fonte: Adaptado da SABESP (2018).

A resolução CONAMA 357/05 (BRASIL, 2005) estabelece valor mínimo de 5 mg.L $\mathrm{L}^{-1}$ de oxigênio para corpo de água doce classe II. As concentrações de OD, no ponto BL 105, variaram de 5,90 a 10,1 mg. $\mathrm{L}^{-1}$ e média de $8,34 \pm 1,37 \mathrm{mg} . \mathrm{L}^{-1}$, estando em todo o período de estudo de acordo com a legislação vigente, no entanto, essas concentrações altas de OD estão relacionadas com o bloom de algas e indicam de forma direta que a região do Braço Taquacetuda, apresenta-se em estado de eutrofizado (CETESB, 2018).

No entanto, quando analisadas as mensurações para o ponto GU 101, foi verificado que, nos meses de janeiro e fevereiro de 2018 (período chuvoso), concentrações de 3,1 e 4,8 mg. $\mathrm{L}^{-1}$, respectivamente, estava abaixo do estabelecido, o que podem estar relacionado com as concentrações de fósforo e DBO gerando maior consumo do oxigênio para a degradação da matéria orgânica. A Figura 7, apresenta as concentrações de OD nos dois pontos, em todo o período de estudo.

Quanto ao parâmetro biológico das cianobactérias, que são organismos fitoplanctônicos, que podem trazer sérios problemas ambientais e de saúde pública (BELÓ; MATHIAS; GONTARSKI, 2018), sua ocorrência em ambientes aquáticos está ligada a altas concentrações de nutrientes (MACHADO et al., 2016).

As concentrações de cianobactérias quantificada para o ponto BL 105 variaram entre $67 \times 10^{5}$ a $267 \times 10^{5}$ cél. $\mathrm{mL}^{-1}$ com média de $159 \times 10^{5} \pm 69 \times 10^{5}$ cél. $\mathrm{mL}^{-1}$. Em todos os meses de análises, foram verificadas concentrações de cianobactérias acima do estabelecido pelo CONAMA 357 (BRASIL, 2005) que é de 50x105cél. $\mathrm{mL}^{-1}$, constatando que os valores elevados de células de cianobactérias ocorreram independentes do efeito da sazonalidade, pois mantiveram-se elevados os registros tanto no período chuvoso como no período seco. O aumento desses organismos está relacionado a fatores abióticos (nutrientes, temperatura e luminosidade) que atuam de forma direta na proliferação (CETESB, 2017). Fatores preponderantes para esses altos valores se dá pela poluição do reservatório, pelo bombeamento do rio Pinheiro e na ocupação antrópica das bacias de drenagem do ribeirão Cocaia e ribeirão Bororé (CETESB, 2018).

SILVA, R. A. S., MICHELAN, D. C. G. S. 
Quando analisadas as concentrações de cianobactérias no ponto GU 101, que recebe as águas provenientes do ponto BL 105, essas variaram entre $8 \times 10^{5}$ a $123 \times 10^{5}$ cél. $\mathrm{mL}^{-1}$ com média $29 \times 10^{5} \pm 32 \times 10^{5}$ cél.mL $L^{-1}$. Nesse ponto, apenas no mês de junho de 2018 (seco), apresentou-se acima do estabelecido pela norma vigente.

A Figura 8 apresenta a comparação das concentrações de cianobactérias dos pontos analisados. Os altos valores de cianobactérias, podem dificultar o tratamento da água que é utilizada para abastecimento, sendo necessária a utilização de tratamento avançado.

\section{Figura 7 - Gráfico contendo os valores de OD mensurados para os pontos analisados, frente ao limite mínimo do CONAMA $357 / 2005$, que é de $5 \mathrm{mg} \cdot \mathrm{L}^{-1}$.}

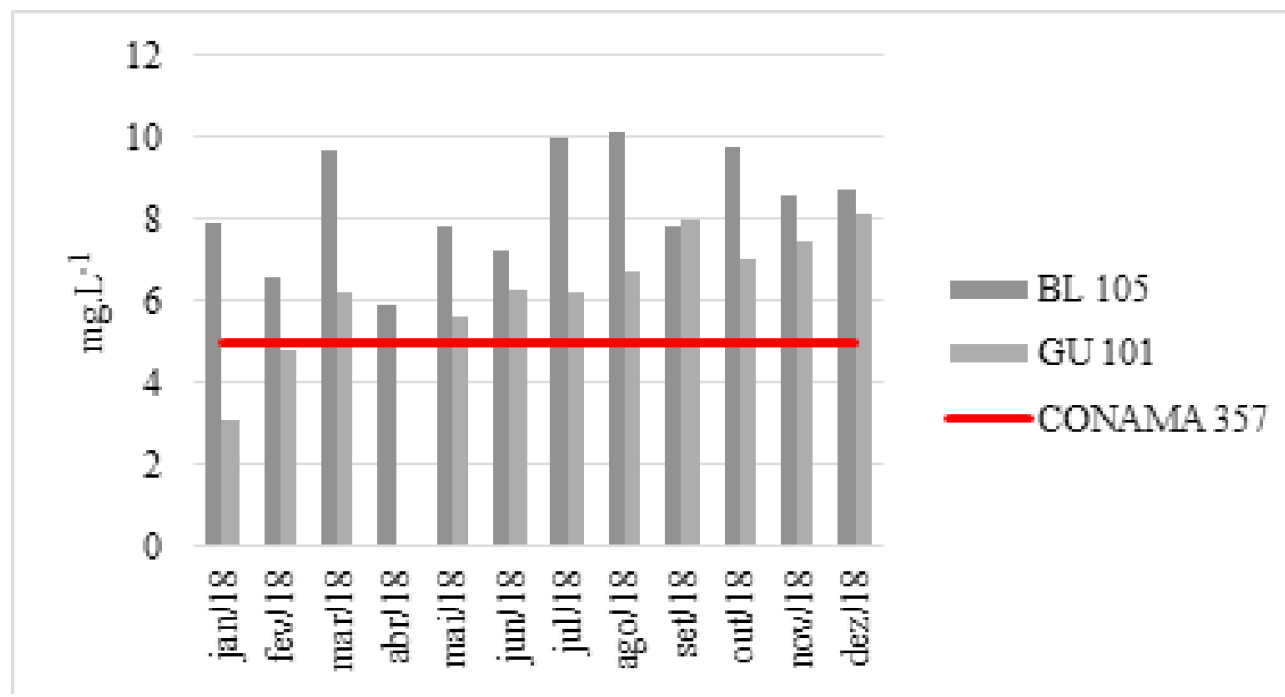

Fonte: Adaptado da SABESP (2018).

Figura 8 - Gráfico apresentando as concentrações de cianobactérias.

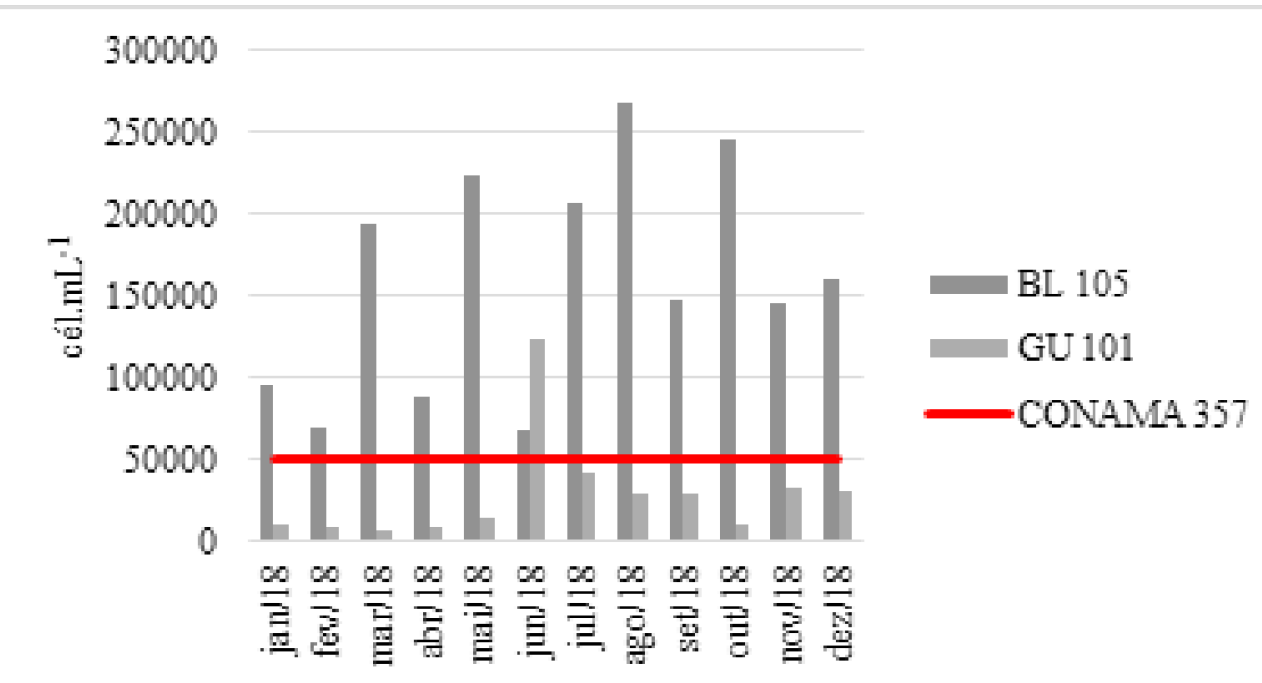

Fonte: Adaptado da SABESP (2018). 


\section{Considerações Finais}

Diante das análises das águas transferidas pelo Sistema Produtor Taquacetuba - Guarapiranga por meio dos parâmetros de qualidade de água, concluiu-se que os parâmetros cor aparente, $\mathrm{pH}$, turbidez, Escherichia coli, nitrogênio amoniacal, nitrato e nitrito, apresentaramse em concentrações de acordo com a norma vigente. Já os significativos valores de fósforos mensurados indicam que as águas estão em estado eutrófico. E consequentemente, responsável pela concentração de cianobactérias. Sendo assim, é necessário que medidas de controle e gestão nas duas represas sejam realizadas, para evitar que problemas sejam causados à saúde da população, tendo em vista, que as cianobactérias apresentam toxinas que são de difícil remoção. Além disso, deve-se considerar que as fontes de poluição difusa contribuem com a problemática.

\section{Referências}

BELÓ, A.; MATHIAS, A. L.; GONTARSKI, C. A. U. Comparison of the physical, chemical and biological parameter magnitudes and cyanobacteral bloom in the Alagados reservoir of Ponta Grossa - PR. Revista. Ambiente e Água, Taubaté, v.13, n.3, p. 2-12, fev 2018.

BRASIL. Conselho Nacional do Meio Ambiente - CONAMA, Resolução n. 357, de 17 de março de 2005. Dispõe sobre a classificação dos corpos de água e diretrizes ambientais para o seu enquadramento, bem como estabelece as condições e padrões de lançamentos de efluentes, e dá outras providências. Diário Oficial da União, Brasília. 2005.

BRITO, F. M. de; MIRAGLIA, S. G. E. K; SEMENSATTO, D. Ecosystem services of the Guarapiranga Reservoir watershed (São Paulo, Brazil): value of water supply and implications for managent strategies. International Journal of Urban Sustainable Development, v.10, n.1, p. 49-59, fev 2018.

COBRAPE - Companhia Brasileira de Projetos e Empreendimentos. Relatório Final Atualização do Plano de Desenvolvimento e Proteção Ambiental da Bacia Hidrográfica do Guarapiranga. São Paulo. Governo do Estado de São Paulo, Secretária do Meio Ambiente do Estado de São Paulo, 2006.

COMPAHIA AMBIENTAL DO ESTADO DE SÃO PAULO -CETESB, Caracterização da Bacia do Alto Tietê. São Paulo. Governo do Estado de São Paulo, Secretária do Meio Ambiental, 2015.

COMPAHIA AMBIENTAL DO ESTADO DE SÃO PAULO -CETESB, Qualidade das águas interiores no Estado de São Paulo. São Paulo. Governo do Estado de São Paulo, Secretária do Meio Ambiental, 2017.

COMPANHIA AMBIENTAL DO ESTADO DE SÃO PAULO - CETESB. Significado Ambiental e Sanitário das Variáveis de Qualidade. São Paulo. Governo do 
Estado de São Paulo, Secretária do Meio Ambiente, 2018.

COMPANHIA DE SANEAMENTO BÁSICO DO ESTADO DE SÃO PAULO-

SABESP. Monitoramento da qualidade da água da transferência do Braço Taquacetuba

(Billings) para a Represa Guarapiranga. Departamento de Recursos Hídricos Metropolitanos, 2018.

DALMAS, F. B.; VARGAS, R. R.; SAAD, A. R.; ANDRADE, R. M. de; ANDRADE, J. A. de; ARRUDA, R. de O. M. Reflexos do uso e ocupação do solo na qualidade da água do rio Embu-Guaçu, Região Metropolitana de São Paulo. Revista. Geociências, São Paulo, v. 34, n. 1, p. 130-144, 2015.

DEPARTAMENTO DE ÁGUAS E ENERGIA ELÉTRICA DO ESTADO DE SÃO PAULO -DAEE. Portal do departamento de águas e energia elétrica. Disponível em: < http://www.daee.sp.gov.br/> acesso em: 08 mai. 2019.

FAUSTINO, S. B.; FONTANA, L.; BARTOZEK, E. C. R.; BICUDO, C. E. de M.; BICUDO, D. de C. Composition and distribution of diantom assemblages from core and surface sedimentes of a water supply reservoir in Southeastern Brazil. Biota Neotropica, Campinas, v. 16, n.2, p. 2-23, 2016.

FONTANA,L.;ALBUQUERQUE,A.L.;BRENNER,M.;BONOTTO,D.; SABARIS, T.; PIRES, M. A. F.; COTRIM, M. E. B.; BICUDO, D. The eutrophication history of tropical water supply reservoir in Brazil. Journal Paleotimnol, v. 51. p. 29-43. Nov 2014.

GOIS, J. S; OLIVEIRA, F. H. P. C. Variação sazonal das cianobactérias como parâmetro para analise da qualidade da água do reservatório Mororó, no município de Pedra/PE.Rev. Brasileira de Geografia Física, v.07, n.05, 1015-1023, 2014.

GUEDES, H. A. S.; SILVA, D. D. DA; ELESBON, A. A. A.; RIBEIRO, C. B. M.; MATOS, A. T. DE; SOARES, J. H. P. Aplicação da análise estatística multivariada no estudo da qualidade da água do Rio Pomba, MG. Revista Brasileira de Engenharia Agrícola e Ambiental, v. 16, n. 5, p. 558-563, 2017.

MACHADO, L. dos S.; SANTOS, L. G.; DOVAL, J. C. L.; POMPÊO, M. L.; MOSCHINI-CARLOS, V. Fatores ambientais relacionados à ocorrência de cianobactérias potencialmente tóxicas no reservatório de Guarapiranga, SP, Brasil. Revista Ambiente e Água, Taubaté, v.11. n.4. p. 811-818, Ago 2016.

MENEZES, L. C. B. de; GARGIULO, J. R. B. C.; MONTEIRO-JUNIOR, A. J. Qualidade da água em locais de pesca artesanal no complexo Billings, São Paulo. Revista Ecologia e Meio Ambiente, v. 30, n. 1. p. 43-53, 2016.

MORAIS, M. R. D. de; OLIVEIRA, M. M.; OLIVEIRA, V. de P. S. de. Impacto da ação antrópica na qualidade da água da represa de Juturnáiba-Silva Jardim/RJ. Revista 
Boletim do Obeservatório Ambiental Alberto Ribeiro Lamego. Campo do Gotacazes, v. 10, n.1, p. 201-233, 2016.

QUEIROZ, W. de; OLIVEIRA. A. M.; ROSSI, M.; SAAD, A. R.; ANDRADE, M.

R. M. Análise geoambiental da bacia do Guarapiranga, Região Metropolitana de São Paulo: Produção de sedimentos e assoreamento do reservatório. Revista Brasileira de Geomorfologia. São Paulo, v.16, n. 1, p. 89-105, 2015.

POMPÊO, M.; CARLOS-MOSCHINI, V.; LÓPEZ-DOVAL, J. C. ABDALLAMARTINS, N.; CARDOSO-SILVA, S.; FREIRE, R. H.F.; BEGHELLI, F.G. de .; BRANDIMARTE, A. L.; ROSA, A. H.; LOPEZ, P. Nitrogen and phosphorus in cascade multi-system tropical reservoirs: water and sediment. Revista. Limnological. v.17, n.3, p. 133-150, jan 2017.

SCHMITZ, A.P.; BITTENCOURT,M.V.L. Crescimento econômico e pressão sobre recursos hídricos. Revista Estudos Econômicos. São Paulo, v. 47, n. 2, p. 329-363, 2017 TADEU, M. S.; DALMAS, F. B.; COSTA, R. A.; SAAD, A. R. Conflitos decorrentes da ocupação do solo nas margens da represa Guarapiranga, no município de Embu Guaçu, em consonância com a legislação ambiental vigente. Revista Principia, João Pessoa, n. 33. p.21-28, Mai 2017.

YAN, W.; LI, J.; BAI, X. I. Comprehensive Assessment and Visualized Monitoring of Urban Drinking Water Quality. Chemometrics and Intelligent Laboratory Systems, v.155, 26-35, Jul 2016.

VÉLEZ-AZANERO, A.; LOZANO, S.; CÁCERES-TORRES, K. Diversidad de fitoplancton como indicador de calid de agua em la Cuenca Baja del Río Lurín, Lima, Peru. Revista Ecología Aplicada, Lima, vol.15, n.2, 2016. 